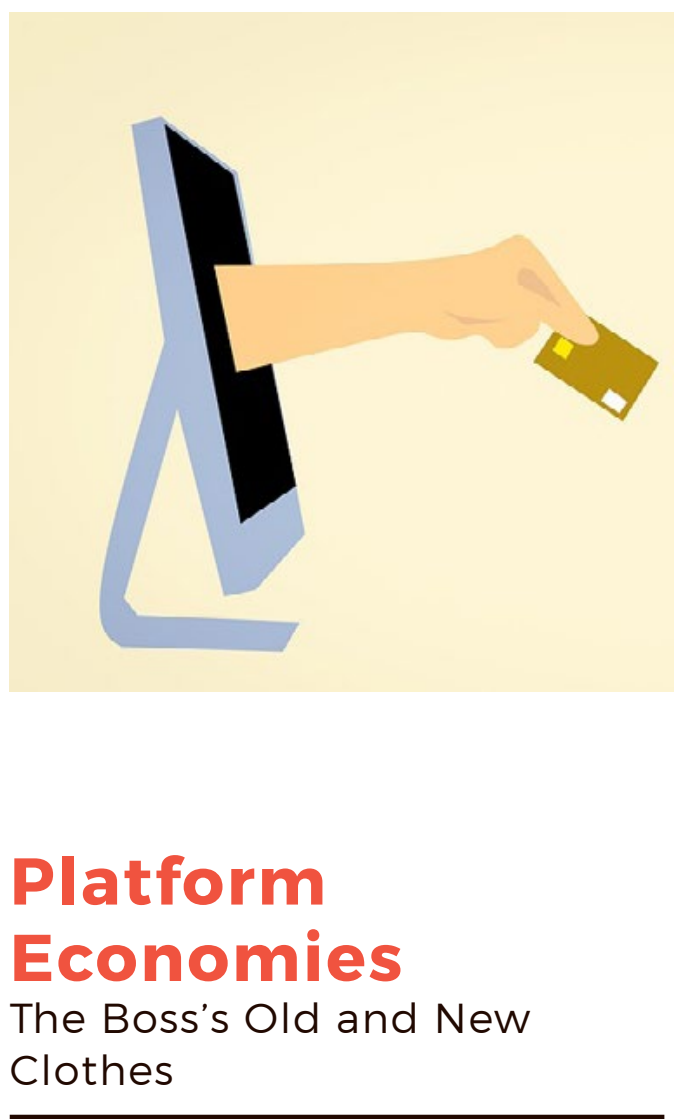

Julie Yujie CHEN

The recent growth of China's platform economy is jaw-dropping. What Chinese platform workers have experienced is the epitome of the intertwining transformations that digital technologies have engendered, not only in the Chinese economy and society, but also in global capitalism more generally. In this essay, Julie Chen argues that a better understanding of the situation of these workers will inform us about China's economic conditions and provide a glimpse into the future of Chinese labour struggles.

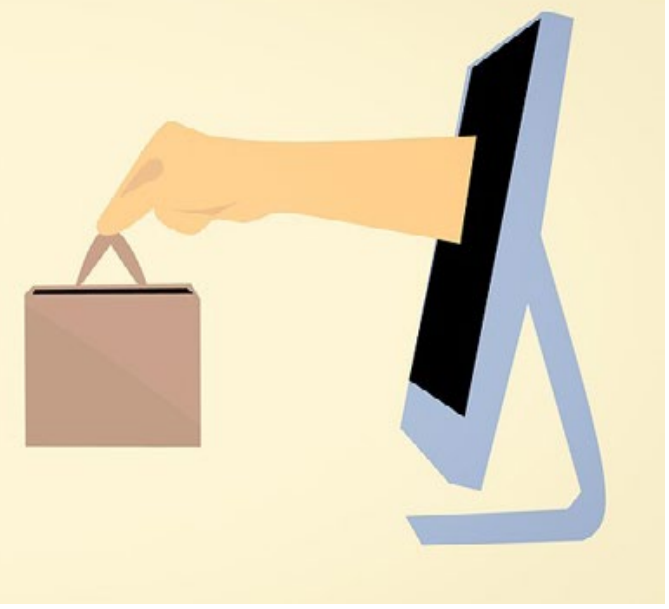

'Selling Online,'

PC: maxpixel.net.

$\mathrm{n}$ the eyes of both China scholars and the public, the recent growth of China's Internet economy is jaw-dropping. Not only did Baidu, Alibaba, and Tencent enter the top ten most valuable tech companies in the world, but new players have also emerged on the global stage. For instance, ride-hailing platform Didi Chuxing, mobile payment methods Alipay and WeChat Pay, and bicyclesharing platforms Mobike and ofo have become household names all over the world because of their rapid success and global presence.

The 'platform economy'-a term loosely used to describe the economic activities that are performed by Internet platforms-is estimated to have facilitated transactions worth more than 49 billion yuan (7.7 billion USD) in 2017, involving 700 million users and 70 million workers (China's National Information Center and Internet Society of China Sharing Economy Committee 2018). According to my calculations based on data included in the China Statistical Yearbook (2017), in 2016 the platform economy absorbed 18 percent of the labour force in the tertiary industry. Moreover, an annual increase of ten million workers since 2015 makes the platform economy the fastest growing sector 
in China (China's National Information Center and Internet Society of China Sharing Economy Committee 2016, 2017, 2018). In the meantime, widespread labour disputes and unrest also make it a site for more labour struggles (CLB 2017, 2018).

Because of the pressure on economic restructuring in the aftermath of the 2018 financial slowdown, and thanks to support from the central government, China's platform economy shows no sign of slowing down. What Chinese platform workers have experienced is the epitome of the intertwining transformations that digital technologies have engendered not only in the Chinese economy and society, but also in global capitalism more generally. Consequently, a better understanding of the situation of these workers will inform us about China's labour and economic conditions, as well as about more general challenges in terms of inclusive and sustainable development with implications that have relevance far beyond China. This essay aims to shed light on these dramatic and overlapping transformations by highlighting two related tensions.

\section{Old Wine in New Bottles?}

The first tension exists between a persisting struggle of workers against 'the same old problems' and an emerging new set of challenges related to new modalities of value extraction in the platform economy. It is evident that Chinese workers in the so-called 'new economy' are still fighting against traditional forms of exploitation, like wage theft and unilateral termination of contracts without compensation (CLB 2016). Drivers working on the ride-hailing platforms, for instance, still protest against illegal vehicles and high monthly fees paid to the car companies (Chen 2018; CLB 2018). Nonetheless, the 'old wine in new bottles' of labour struggles should not distract attention from a fundamental shift happening to the value accumulation mechanism in the platform economy-i.e. the fact that the platform economy is, by nature, a form of data capitalism (Srnicek 2016). Data is the foundation upon which a digital platform functions and continues to exist-without data, algorithms cannot work; without a continuous influx of data into the platform system, algorithms cannot improve; without properly functional algorithms, the platform would fail.

A number of scholars have started to grapple with the implications of massive data collection for democracy and the ways in which it is transforming political economy at national and global levels (Foster and McChesney 2014; Zuboff 2015). Big data collection affects all participants in the platform economy, but workers always face more intensive data capture, and harsher control and discipline enacted through algorithms. For instance, the 531,000 delivery riders at Meituan-the largest online takeaway platform, which performed 2.9 million deliveries per hour during the daily peak time in 2017 (Meituan-Dianping 2018)are all subject to the platform's commands for dispatching and route planning. The 2.9 million hourly deliveries could have never been accomplished without constant influx of real-time data about riders' mobility and performance.

At the core of value extraction and accumulation in the platform economy is a continued trend of shifting surplus away from workers and the general population, and towards capitalists by means of financialisation and automation (Dyer-Witheford 2015). Platform workers' livelihoods, welfare, and reproduction are entangled in data production and manipulation for the growth of the digital platforms, just as factory workers are caught up in the processes of industrialisation. This does not mean to suggest that industrialisation and legacy labour struggles have stopped being relevant nowadays, but that capitalism's turn to datafication has not yet captured substantial interest among labour scholars. It should. Its profound implications for Chinese workers are all the more significant and urgent against the backdrop of China embracing digital 
technologies for development and governance. The state's centralised data infrastructure is under construction with projects like the social credit system that incorporates both public and private sectors and will be used for political, economic, and social governance (Liang et al. 2018; see also Loubere and Brehm's essay in this volume). Establishing meaningful connections between day-to-day worker struggles and the structural shift to data capture is a daunting task on the horizon for scholars, workers, and activists alike.

\section{Outside the Law?}

The second tension emerges between the momentum of what Ching Kwan Lee refers to as 'decentralised legal authoritarianism'-i.e. the central government's institutionalised regime to contain workers' collective actions at the local level-and the elusive position of platform companies that are at once implicated in the local informal labour market, yet are also able to get around local regulations (Lee 2007). The dominance of informal labour in China sets in motion a distinctive trajectory of platform economic behaviour. From the e-commerce boom to the ride-hailing market, platform economies rely heavily on the large pool of cheap and informal labour. Take ridehailing platforms as an example. Instead of disrupting the traditional taxi industry, most of them-including Didi Chuxing which controls more than 90 percent of the market-also retain traditional taxi services on the platform along with other transport services like ride-sharing. In this way, Chinese ride-hailing platform companies build on the vast pre-existing grey market of illegal and informal taxi services (Chen 2018). This grey market exists in the first place because of the labour segmentations produced by state-owned taxi enterprises and the vastly different regulations at the local levels (Chen 2018). Traditional taxi drivers in one city may find their challenges different from those faced by their counterparts in the neighbouring city or province. They fight local battles, face decentralised regulations, and find it difficult to mobilise for a nationwide cause, which is analogous to other worker struggles as observed by Lee (2007). This pattern carries on to the ride-hailing market as regulations go local.

Ride-hailing apps were legalised in 2016 with the intention to standardise and regulate the market. By the end of 2017, more than 210 municipal governments have passed localised bylaws to regulate the ride-hailing market (China's National Information Center and Internet Society of China Sharing Economy Committee 2018). Local regulations stipulate licence criteria and application procedures for vehicles, drivers, and ride-hailing platform companies. For example, Beijing mandates a 'double-local' rule-that is, only drivers with Beijing hukou operating vehicles with Beijing licence plates are eligible to work legally on the platforms (Beijing Transportation Committee 2016). Shenzhen, a migrant city, requires one-year proof of residence in the city from an applicant driver, but in the spring of 2018 it ruled that only electric cars can be used to apply for the operational licence for ridehailing services (Shenzhen Transportation Committee 2016, 2018). Local policies that set various requirements for vehicles and drivers indeed embody the needs of local authorities, whether for managing population mobility, stimulating new industries, or a variety of other reasons. But the relationship between drivers and platforms is left mostly undefined across the nation and, as a result, platforms have little legally mandated responsibility for drivers' work conditions, social security, and long-term welfare.

Policy orientation of this kind is more likely to make drivers' lives more precarious than to pressure platform companies into compliance. As of June 2018, Didi Chuxing had legal operational licences in only 51 cities out of the more than 400 cities where it operates (Yue 2018). In 2017, it was also reported to have participated in recruiting unqualified drivers to work on the platform (Yangtze Evening 
Paper 2017). This quasi-legal position not only fails to prevent the company from collecting massive amounts of data and accumulating value through its information network, but also puts a majority of drivers in a collectively vulnerable position because of illegitimacy de jure. They suffer the brunt of market volatility, as well as the penalties inflicted by suddenlytightened local regulations. For instance, drivers in Beijing, if caught in violations of rules, face up to 30,000 yuan of fines and the temporary seizure of their driver's licence (innoinsights 2018).

\section{Beyond Cyber-control}

The relationship between drivers, ridehailing platforms, and regulatory bodies at different levels is symptomatic of the economic and regulatory environment for the platform economy. Platform companies thrive because of the network effect of digital technologies (Srnicek 2016), as well as their brazen violation of regulations. They also thrive by taking advantage of the existing informal labour market and reinforcing labour segmentation. Subcontracting prevails in sectors like online food-delivery and logistics. Platform companies control the labour process via algorithms across geographies (Rosenblat and Stark 2016), which renders them increasingly significant actors in labour management and segmentation.

It is important to point out that labour control of Chinese on-demand platform workers also goes far beyond the level of algorithms. It takes the shape of both a network and a hierarchy when 'decentralised' regulations compound the effects of cybernetic systems imposed by platforms. In the same way that social media platforms curate users' online content and by extension shape public discourses (Gillespie 2018), digital work platforms broker economic rewards, risks, and opportunities among workers. A clearer definition of platform companies' intermediary and governing roles, and the correspondent liability in the legal framework, is in order.

Indeed, there are many other noteworthy aspects of platform economies in China that this essay does not elaborate on, such as the discourse of flexible work as a new type of employment and robust workers' selforganisations. The two tensions outlined above do not exist in isolation. They intersect. They both contain something old and something new. It is the elusive combination of 'boss's old and new clothes' in the platform economy that underlines the high stakes for regulators and Chinese platform workers-not to mention the working class in general. 
This text is taken from Dog Days: A Year of Chinese Labour, Civil Society, and Rights, Made in China Yearbook 2018, edited by Ivan Franceschini and Nicholas Loubere, published 2019 by ANU Press, The Australian National University, Canberra, Australia.

doi.org/10.22459/MIC.04.2019.18 